\title{
Infections in Prison in Low and Middle Income Countries: Prevalence and Prevention Strategies
}

\author{
Oscar O. Simooya*
}

IN BUT FREE Prisons Project, P.O. Box 22521, Kitwe, Zambia; and Copperbelt University, P.O. Box 21692, Kitwe, Zambia

\begin{abstract}
Prisoners throughout the world are at a greater risk of infectious diseases compared to communities outside. Hepatitis C (HCV), human immunodeficiency virus (HIV) and tuberculosis (TB) have attracted great attention because of their potential to cause great morbidity and mortality in prison populations.

However, prisons are not closed worlds. Many people enter and leave prisons every day and many prisoners themselves stay only a short period in prison and return to their families. Giving prisoners adequate treatment for infectious diseases is good medical practice and provides public health benefits to the community.

There are several factors that may fuel the highly infectious environment in prisons and include: 1) poor health services; 2) overcrowding and congestion; 3) high risk behaviors; 4) security vs public health concerns and 5) lack of public empathy for prisoners. This paper looks at the challenge of infectious diseases in prisons in low and middle income countries (LMICs).

Three percent of the world's population is infected with HCV but in prisons the prevalence appears to be much higher ranging from $4 \%$ in Indian prisons to $12.3 \%$ in prisoners in Nigeria. A review of HIV prevalence in 152 LMICs found information on HIV prevalence in only $75(50 \%)$ of these countries. HIV prevalence was greater than $10 \%$ in prisons in 20 countries. TB infection rates in prison are equally high and may be up to 100 times those outside prison.

Overcrowding is a major problem and non-custodial sentences must be considered in order to decongest prisons. Furthermore, standard medical treatment and prevention measures for HCV, HIV and TB must be provided to prisoners in order to reduce the burden of infections in prisons. Linkages between prison health and national health services would go a long way in addressing the threat of infections to prison populations.

Prisoners go to jail to be punished for offending society and not to get infectious diseases. Health care equivalent to that found outside prison must be provided to these individuals.
\end{abstract}

Keywords: Hepatitis, HIV, tuberculosis, prisons, LMICs.

\section{INTRODUCTION}

Several health problems confront inmates living in prisons all over the world and include both physical and mental illnesses. However, the advent of the AIDS epidemic some 30 or so years ago has added impetus to the realization that prisoners are at a greater risk of both HIV infection and closely associated infections. Although prisoners may be vulnerable to a wide variety of infections, hepatitis $\mathrm{C}$ (HCV), human immunodeficiency virus (HIV) and tuberculosis (TB) have received much attention because of their potential to cause great morbidity and mortality in prison populations.

Whatever the case maybe, prisons are not closed off worlds. Many people enter and leave prisons every day. These include prison staff, lawyers, social workers, health personnel, the clergy and prisoners' family members. Many prisoners themselves stay only a short period in prison and return to their families. It is estimated, for instance, that although the world wide prison population is over 9 million, the annual turnover is closer to 30 million [1].

*Address correspondence to this author at the Copperbelt University, P.O. Box 21692, Kitwe, Zambia; Tel: +260 212 222206/227796; Fax: +260 212 228319; E-mail: oscar.simooya@cbu.ac.zm
Given, this high movement of people into and out of prisons, the possibility of infections acquired in prison being transmitted outside is very high. Giving prisoners treatment for infectious diseases is good medical practice and provides public health benefits to the wider community. Measures to address the highly infectious conditions in prisons are therefore needed and needed urgently.

This paper considers the challenge of infectious diseases in prisons in low and middle income countries (LMICs), regions of the world already burdened with high morbidity and mortality of infectious diseases. The World Bank [2], classifies LMICs as countries with an income of USD 975 or less to USD 11,905. From this definition, most LMICs are in Africa, Eastern Europe and Asia, Latin America and the Caribbean. These countries are sometimes also referred to as "developing countries".

\section{WHY ARE PRISONS CONDUCIVE TO INFECTIOUS DISEASES?}

There are several factors that contribute to the highly infectious environment in prisons. However, the following appear to play a very important role: 1) poor health systems; 2) overcrowding and congestion; 3) demographic 
characteristics of prisoners themselves; 4) security $v s$ public health concerns and 5) lack of public empathy for prisoners.

\section{Poor Health Systems}

Although it is generally agreed by public health authorities globally that inmates in prisons and other correctional facilities are entitled to the same level of preventive measures available in the community [3], it is now recognized that prisoners in many countries are given less protection against infectious diseases compared to services available outside prison [4]. Furthermore, whereas Principle 9 of the United Nations Basic Principles for the Treatment of Prisoners calls for equivalence of health care between that provided for prisoners and that available in each country without discrimination [5], several reports lament the poor quality of health care in prisons throughout the world [68].

\section{Overcrowding and Poor Living Conditions}

In addition to having weak health systems, many prisons throughout the world are overcrowded, have poor living conditions and often inmates are offered diets of limited nutritional value. Infections, especially airborne diseases such as tuberculosis, thrive best in overcrowded and unhygienic environment. Similarly, poor nutrition will contribute greatly to the vulnerability of individuals exposed to infective agents.

Of the total of 9.8 million people held in prisons on a daily basis world wide in 2008, the largest population of prisoners in the LMICs were in China $(1.5$ million) and 0.89 million in Russia [1]. However, whatever the prison population could be in any individual country, most prisoners in LMICs were often kept in facilities with very limited holding capacity and often with poor sanitation and hygiene.

Many reports have alluded to overcrowding and poor living conditions affecting most of the world's prisons. A report by the Asian Human Rights Watch [9], laments the poor living conditions for prisoners in India, Sri Lanka, Afghanistan, Thailand and Hong Kong. In Brazil it is reported that many prisons keep two to five times more prisoners than they were meant to [10], while in Venezuela, the country's prisons kept over 24, 000 prisoners in facilities meant for 15, 000 [11].

A report from South Africa, decries the situation where 160,000 prisoners were kept in cells with a holding capacity of 114,000 , a finding that led to the country's Auditor General to rebuke the correctional services for violating the law [12]. In Zambia, the population in the country's prisons was 14,500 in 2004 against a capacity of 8,000 [13]. The major prison in the capital city, Lusaka had 1,600 inmates in facilities meant for just 260 people.

Across the Zambian border in Malawi, it was reported that in June 2009 alone, over 100 prisoners died at the Chichiri Prison, in the commercial city of Blantyre due to diseases brought about by overcrowding and the poor living conditions in many of the country's prisons [14].

\section{Socio Demographic Characteristics of Prisoners}

Prisons are full of young people with a background of high risk behavior prior to incarceration. In most countries prisoners come from the poor, uneducated and disadvantaged communities and are therefore more likely to be at risk of infectious diseases. In studies in Zambian prisons, a history of multiple sexual partners was highly associated with having HIV infection [15] while a large number of prisoners in Eastern European prisons and the Far East are in custody for injecting drugs [16].

\section{Security vs Public Health Concerns}

In general, prisons are high security institutions and this means that the needs of maintaining security may frequently appear to be more pressing and could at times be in conflict with genuine public health needs. For instance, whereas the isolation of a prisoner with a highly infectious disease might be considered urgent and a normal public health consideration, many a prison administrator would mull over the implication of the decision security wise.

Additionally, because of the same fears, the flow of people with expertise in infection control into and out of prisons may not be as easy as for instance the ease with which they gain access to other public institutions.

Then there is the legal problem posed by some of the risk behaviors that may cause the transmission of infectious diseases in prisons. In many countries, sex between people of the same gender, let alone homosexuality is a criminal offence and offenders could be sentenced to five years or more in jail [17]. In these circumstances prison authorities and indeed inmates themselves have found it difficult to deal with this subject and sometimes discussion on this matter may be seen as condoning illegal acts.

The use of intravenous drugs is another difficult issue [18]. Although it is well known that drugs are consumed in prisons, drug use is illegal and once discovered it is usually met with disciplinary measures, not public health measures.

\section{Lack of Public Empathy for Prison Programs}

From time immemorial prisoners have had a very low status in society and the general belief by most people is that prisoners are sent to jail to be punished for offending society [19]. Therefore initiatives that appear to assist prisoners are not readily supported. This has meant that even within prison establishments themselves, allocating funds for the welfare of prisoners is often a low priority.

\section{PREVALENCE OF INFECTIOUS DISEASES IN PRISONS}

Despite the fact that prisons are acknowledged as institutions with a high burden of infectious diseases, data on the extent and magnitude of these infections is to a large extent unavailable and often incomplete. Well documented information on prevalence rates of infectious diseases in prisons have therefore come mainly from studies conducted in developed countries. Three infections in particular, hepatitis C (HCV), human immunodeficiency virus (HIV) and tuberculosis (TB) have the potential to cause severe morbidity and mortality in prisons.

\section{Hepatitis C}

Hepatitis C (HCV) is transmitted through blood or blood products. It is therefore common in individuals who inject drugs, those who practice tattooing and in those who engage in other blood letting rituals such as blood brotherhood initiation ceremonies. This epidemiological picture suggests that prisons are fertile grounds for the spread of $\mathrm{HCV}$ due to 
the presence of these high risk behaviors in prison populations.

The World Health Organization (WHO) estimates that $3 \%$ of the world's population is infected with $\mathrm{HCV}$ but in prisons the prevalence is much higher, from the $4 \%$ found in a study in Indian prisons [18], to equally high prevalence reported in Iran [20, 21], Brazil [22], Ghana [23] and Nigeria [24] where $12.3 \%$ of inmates had HCV infection.

\section{Human Immunodeficiency Virus (HIV)}

The prevalence of HIV infection in prisons varies from country to country but it is often much higher than that found in communities outside. The high rates of HIV infection in prisons appear to be fuelled by several factors including large numbers of incarcerated IDUs, male to male sex which maybe consensual or forced, blood letting incidences such as initiation ceremonies (blood brotherhood), tattooing and sharing of contaminated razor blades.

A recent review of HIV prevalence in 152 LMICs found information on HIV prevalence in only $75(50 \%)$ of these countries. The authors report that HIV prevalence was greater than $10 \%$ in prisons in 20 countries and evidence for HIV transmission in prison was found in seven countries [25].

In Zambia, an HIV prevalence rate of $27 \%$ was reported in 2001, a prevalence rate much higher than the then national average of $19 \%$ [15]. Male to male sex and tattooing were identified as risk behaviors for HIV transmission in the country's prisons. Other sub Saharan countries report similarly high HIV prevalence in prisons: Burkina Faso, $11 \%$; Cameroon, $12 \%$; Cote d' I voire, a study in the main prison facility in Abidjan reported a prevalence of $27.54 \%$ compared to $12-14.2 \%$ in the urban areas of the country; Rwanda 14\%; South Africa 45\% and Tanzania, 6\% [16].

In the Russian Federation, $4 \%$ of prisoners were living with HIV and AIDS, while in Vietnam and Indonesia, the HIV infection rate was $28 \%$ and $15 \%$ respectively [18]. In Brazil and Cuba, prevalence rates in prisons were $15 \%$ and $26 \%$ respectively (ibid).

\section{Tuberculosis}

The World Health Organization (WHO) reports that the rates of TB infection in prisons are much higher than in the communities outside prison and adds that the rate multi drug resistant (MDR TB) has risen considerably in LMICs notably in the former Soviet Union, East Asia and Sub Saharan Africa [26].

Although data is limited, some reports suggest that TB infection rates in prison may be up to 100 times more common in prison than outside prison and up to a quarter of any country's TB cases may be found in prison. The International Red Cross reports that the rate of TB infection in Kyrgyzstan prisons was 40 times that in the civilian population while in Peru, the TB infection rate in prison was 49 times that outside prison [27, 28].

In sub Saharan Africa TB infection rates are equally high in prisons. In Botswana, 3,797/100,000 [29], Malawi $1,100 / 100,000$ [30] and Zambia a large national survey found the TB infection rate of $4,000 / 100,000$ people [31].

\section{STRATEGIES FOR PREVENTING INFECTIOUS DISEASES IN PRISONS}

For any intervention to be successful, it must be appropriate and relevant to the socio cultural situation existing in the target community or society. This being the case, it is clear that for prisons, the complex moral, cultural and legal issues need careful consideration in order to develop successful programmes against infectious diseases.

This paper has argued that the main factors responsible for the high disease burden in prisons are overcrowding and congestion, the poor health care system, the security concerns $v s$ public health needs, the socio demographic characteristics of prisoners and the lack of public empathy for prison programs.

Given these problems what then is the way forward? Despite the magnitude of the problems, there is a lot that can be done to minimize the threat of infectious diseases in prisons.

\section{Decongestion of Prisons}

It is perhaps important first of all to understand the nature and role of prisons in society.

The main function of prisons worldwide is to provide safe custody and correction to those who have offended society. A review of the criminal justice system in many countries would go a long way in mitigating the impact of $\mathrm{HCV}$, HIV and TB in prisons. Overcrowding is a direct product of the use of custodial sentences to punish offenders. In many countries up to a third of a country's prison population [32] could be prisoners awaiting trial. Is it not possible therefore to consider alternative forms of punishment in view of the great health problems in prisons?

Non-custodial sentences such as giving offenders the option to pay fines, serve their communities at no fee and a more generous use of the parole system could all assist to decongest prisons. The judiciary has a critical role to play here as the faster dispensation of justice could go a long way in reducing the crowded environment in prisons. In some countries such as Zambia, there has been an attempt to decongest prisons by using open-air prisons [13]. This has eased the problem in some ways but the major prisons remain overcrowded.

\section{Link Prison Health to Public Health}

In order to respond to the threat of infectious diseases in prisons, it is imperative that prison health be linked to the comprehensive systems of national health services. In many countries there was an attempt to develop separate health services for prisons in order to maintain the security nature of prisons. The end result has been a poor quality of health care in the latter.

Under this consideration therefore, access to public health measures readily available in outside prisons for the prevention of infectious disease must be strengthened. For instance, in many countries, the various Prisons Acts prescribe the mandatory requirement for new entrants to undergo comprehensive medical examination. Sadly in many LMCIs this is often not possible and inmates with undiagnosed infections could be the foci of new infections inside. 
Routine microscopy and chest radiography for those with medical histories suggestive of tuberculosis could reduce considerably the incidence of tuberculosis in prisons while the availability of voluntary counseling and testing for HIV and other sexually transmitted infections would assist in identifying those requiring treatment at the earliest possible opportunity. Similarly, immunization against hepatitis should be available in all prisons.

As prisoners ultimately, go back to their communities, any strengthening of the quality of care in prisons will in the end promote public health. The linkage could also assist in the follow up of patients and their treatments thus avoiding the dangers of multiple drug resistant (MDR) TB.

Sexual activity is common in sub Saharan African prisons, but very few countries distribute condoms as it is believed that condom availability in prisons would promote illegal activities [33]. However as condoms have been shown, in several studies to reduce the transmission of sexually transmitted diseases, their introduction in prisons must be considered.

For inmates with a background of IDU, several options exist and include providing the means to clean injecting equipment, use of household bleach, needle exchange programmes, psychosocial support, substitution therapy such as methadone treatment programme, provision of condoms to prevent onward transmission of HIV and encouraging the creation of a non repressive environment for drug users. These measures have been termed harm reduction and have been shown to reduce considerably the risk of transmission through contaminated needles and syringes in some European prisons [34].

Above all, health education programmes for both inmates and staff must be intensified in all prisons in LMICs. In a situation where a climate of fear exists it is imperative for prison authorities and indeed public health experts to provide as much as possible, information and knowledge on infectious diseases and measures to reduce the threat of contacting diseases.

\section{CONCLUSION}

Prisoners go to jail to be punished for offending society and not to get infectious diseases. Denying them health care of a standard equivalent to that found outside jail is a denial of their fundamental human rights. Additionally, the spread of infectious diseases in any community cannot be effectively controlled when in that community a focus of high infection is always present - the threat of infectious diseases spreading from prisons to the communities outside needs to be addressed urgently.

The lack of up to date data on the burden of infectious diseases in LMICs is another area requiring attention before evidence based interventions is developed. In the interim decreasing prison crowding and providing screening for HIV, STD's, and active TB would greatly improve healthcare and reduce the burden of infectious diseases. For individuals with symptoms consistent with active TB, chest radiography and sputum microscopy would be an important addition. Immunization against hepatitis $\mathrm{B}$ and harm reduction has the potential to further decrease spread of infectious diseases.
Public health and the provisions of healthcare within the criminal justice system is an important priority. Improving health within prisons will subsequently improve health within the community since most incarcerated individuals are released into the community.

\section{REFERENCES}

[1] International Centre for Prison Studies. The World Prison Population List. Kings College, London, United Kingdom 2007.

[2] World Bank. World Bank list of economies. World Bank, New York, United States of America 2009.

[3] World Health Organization. Health in prisons. A guide to the essentials of prison health. WHO, Geneva, Switzerland 2007.

[4] UNAIDS. At risk and neglected four key populations. 2006 report on the Global AIDS epidemic. UNAIDS, Geneva, Switzerland 2006; CAP 5; 105 -22.

[5] Basic Principles for the Treatment of Prisoners. UN General Assembly res. 45/111, annex, 45 UN GAOR Supp. (no. 49A), UN doc. no. A/45/49.

[6] Zulficar GR Public health implications of substandard correctional health care. Am J Public Health 2005; 95 (10): 1689 -91.

[7] van Niekerk JP, de V. Lock up and stay: South Africa's sick prisons. S Afr Med 2005; 95(5): 281.

[8] Alexander, J. Death and disease in Zimbabwe's prisons. Lancet 2009; 373:995-6.

[9] Wadhawan J. Prison overcrowding: an overview. htpp:// www.ahrchk.net/index.php [Accessed 18th November 2009].

[10] Human Rights Watch. Behind bars in Brazil. http:// www.hrw.org/reports98/Brazil [Accessed 18th November 2009].

[11] Human Rights Watch. Punishment before trial. http://www.hrw.org/advocacy/prisons/venez.sm.htm [Accessed 18th November 2009].

[12] Mernat Mafirakurewa. http: //www.africanews.com/ S Africa prisons choked to the brim [Accessed 18th November 2009].

[13] Ministry of Home Affairs. Status of current situation in prisons as regards HIV and AIDS. Workshop presentation, Zambezi Source Lodge, Kabwe, Zambia 2006.

[14] Southern Times. Overcrowding deaths hit Malawian prisons, http://www.southerntimes.com [Accessed 18th November 2009].

[15] Simooya OO, Sanjobo N, Sijumbila G, et al. Behind walls: A study of HIV prevalence and risk behaviors in Zambian prisons. AIDS 2001; 15(13): 1741 -4.

[16] United Nations Office on Drugs and Crime (UNODC). UNODC, Vienna, Austria. HIV and prisons in sub Saharan Africa: opportunities for action 2007.

[17] Government of the Republic of Zambia. Section 158. Government Printers, Lusaka, Zambia. Indecent practices between men. Laws of Zambia CAP 146(Penal Code) 1995.

[18] United Nations Office on Drugs and Crime (UNODC). HIV and AIDS in places of detention. UNODC, Vienna, Austria. A toolkit for policymakers, programme managers, prison officers and health care providers in prison settings. 2008.

[19] Gideons International. The New Testament of our Lord and saviour, Jesus Christ. Mathew 1982; 25: 6

[20] Mohtasham AZ, Rezvani M, Jafari SR, Jafari SA. Prevalence of hepatitis $\mathrm{C}$ virus infection and risk factors for drug using prisoners in Guilan province (Iran). East Mediter Health J 2007; 13(2): 25656.

[21] Alizadeh AH, Alavian SM, Jafari K, Yazdi N. Prevalence of hepatitis $\mathrm{C}$ virus infection and its related risk factors in drug abuser prisoners in Hamedan - Iran. World J Gastroenterol 2005; 11(26): 4085-89.

[22] Oliveira ML, Hacker MA, Oliveira SA. et al. 'The first shot': the context of first injection of illicit drugs, ongoing injecting practices, and hepatitis $\mathrm{C}$ infection in Rio de Janeiro, Brazil. Cadernos de Saúde Pública 2006; 22(4): 861-70.

[23] Adjei AA, Armah HB, Gbagbo F, et al. Correlates of hepatitis C virus infection among incarcerated Ghanaians: a national multicentre study. J Med Microbiol 2007; 56:391-97.

[24] Adoga MP, Banwat EB, Forbi JC, et al. Human immunodeficiency virus, hepatitis $B$ virus and hepatitis $C$ virus: seroprevalance, co infection and risk factors among prison inmates in Nasarawa State, Nigeria. J Infect Dev Ctries 2009; 3(7): 539-47.

[25] Dolan K, KiteB, Black E, et al. HIV in prison in low-income and middle-income countries. Lancet Infect Dis 2007; 7:32-41. 
[26] World Health Organization (WHO). Literature review on TB control in prisons. WHO, Geneva, Switzerland 2008.

[27] International Committee of the Red Cross. Managing tuberculosis in prisons. www.icrc.org $/ \mathrm{web} / \mathrm{eng} / \mathrm{siteengO} / \mathrm{nsf} / \mathrm{htm} / \mathrm{all} / \mathrm{kyrgyzstan}$ [Accessed 15th November 2009].

[28] International Committee of the Red Cross. www.icrc.org/web/eng/ siteengO/nsf $/ \mathrm{htm} / \mathrm{all} / \mathrm{n}$ [Accessed 15th November 2009].

[29] Centers for Disease Control and Prevention (CDC). Rapid assessment of tuberculosis in a large prison system, Botswana. MMWR Morb Mortal Wkly Rep 2003; 52 (12): 250-2.

[30] Banda HT, Gausi F, Harries AD, Salaniponi FM. Prevalence of smear positive pulmonary tuberculosis amomng prisoners in
Malawi: a national survey (short communication). Int $\mathrm{J}$ Tuberc Lung Dis 2009; 13(12): 1557-15559.

[31] Habeenzu C, Mitarai S, Lubasi D, et al. Tuberculosis and multi drug resistance in Zambian prisons, 2000-2001. Int J Tuberc Lung Disease 2007; 11(11): 1216-20.

[32] Schönteich M. The scale and consequences of pretrial detention around the world. Justice Initiatives. Publication of the Open Society Justice Initiative 2008; pp. 11-43.

[33] Simooya OO. Acceptability of condoms in an African jail. BMJ $2000 ; 320$.

[34] World Health Organization (WHO). Status paper on drugs, prisons and harm reduction. Copenhagen, Denmark 2005.

(c) Oscar O. Simooya et al.; Licensee Bentham Open.

This is an open access article licensed under the terms of the Creative Commons Attribution Non-Commercial License (http://creativecommons.org/licenses/ by-nc/3.0/) which permits unrestricted, non-commercial use, distribution and reproduction in any medium, provided the work is properly cited. 